\section{JTS}

http://penerbit.uthm.edu.my/ojs/index.php/jts ISSN : 2229-8940 e-ISSN : 2600-7940
Journal of Techno

Social

\title{
Adequate Antenatal Care Visits Among Tribal Women in Bangladesh
}

\author{
A.N.M. Rezaul Karim ${ }^{1 *}$ \\ ${ }^{1}$ Department of Computer Science \& Engineering, \\ International Islamic University Chittagong, BANGLADESH \\ *Corresponding Author
}

DOI: https://doi.org/10.30880/jts.2020.12.01.002

Received 18 Jun 2020; Accepted 21 July 2020; Available online 25 August 2020

\begin{abstract}
Maternal mortality is a global concern, and peaks in developing countries. Adequate antenatal care services (ANCs) are indispensable for the survival of both the mother and the fetus. A global phenomenon leads us to the idea that aboriginal communities are socially more disadvantaged than non-tribal communities worldwide. Hence, the scholarship determines the association of socio-economic standing and adequate use of ANC facilities by Bangladeshi tribal women. This study is a quantitative study using a convenient sampling method. Semistructured questionnaires were used to obtain data on married women $(n=556)$ between the ages of 15-49 who had children aged one year or under. The data were analyzed using the SPSS (version 20) S/W. Associations were developed using Chi-square testing and regression analysis was used in this research. Significance was determined at p-value $<0.10$. Results show that only $29.9 \%$ of pregnant tribal women sought ANC services, of which $13.5 \%$ visited a hospital for ANC services four times or more during pregnancy. A significant association between religion, age at first marriage, and family planning with adequate ANC services was observed. This study concludes that women's education, occupation, state of economy, residence location, and distance from healthcare facilities all positively influence the adequate use of ANC services. Thus, upgrading socioeconomic status, decentralization of health facilities, strengthening family planning program and ensuring educational opportunities for women are recommended for adequate consumption of ANC services.
\end{abstract}

Keywords: Maternal health care services (MHCS), adequate antenatal care services, Tribal women

\section{Introduction}

Maternal mortality because of pregnancy and childbirth complications has ranked elevated globally, accounting for almost 830 maternal deaths daily. This is worse in developing countries, which accounts for $99 \%$ of such deaths, and it mainly occurs in low-income rural areas (Alkema, Chou, Hogan, Zhang, Moller, \& Gemmill, 2016; Mahejabin, Parveen \& Sajani, 2016). In 2015 alone, the disparity in maternal death between developed and developing countries is huge (12:239/10 5 live births), with Bangladesh having 176/ $10^{5}$ live births (World Health Organization, 2016). With a global maternal death ratio of 216 deaths $/ 10^{5}$ live births, efforts are geared towards reducing maternal death below $70 / 10^{5}$ live births by the UN sustainable development goal (SDG)3 by 2030 . With a $58 \%$ global antenatal visit of at least four times, Sub-Sahara Africa and South Asia account for only $49 \%$ and $42 \%$ of pregnant women, respectively (World Health Organization, 2015). During gestation, 31\% of women have four or more appointments for antenatal care in Bangladesh (National Institute of Population Research and Training, 2016).

Antenatal care programs are the first steps to achieve the peak of success for healthy motherhood (Karim, Kamal, \& Islam, 2018). WHO recommends a regular antenatal visit of at least four times on or before 12 weeks of gestation. The WHO also suggests that pregnant women should have their first appointments between 8 and 12 weeks after 
conception and the second meeting during the 24 to 26 weeks of gestation, the third one is within 32 weeks, and the fourth is during 36 to 38 weeks (World Health Organization, 2002; World Health Organization \& United Nations Children's Fund, 2003; World Health Organization, 2006). Nevertheless, this situation has not been reasonably achieved in many developing countries. Women with insufficient prenatal care have a greater risk of adverse outcomes of conception.

A study reveals that an insufficient number of antenatal care visits are associated with a higher risk of underweight baby (da Fonseca, Strufaldi, Carvalho, \& Puccini, 2014). Another study exposed that, in addition to higher negative effects on births such as premature birth, women who are underweight and receive inadequate maternity care (ANC) are at greater risk of complications during pregnancy such as anaemia, eclampsia and preeclampsia (Abbas, Rabeea, Abdel Hafiz, \& Ahmed, 2017). Maternal services in Bangladesh have made some progress over the past decade. However, Bangladesh still has a long way to ensure maternal health services (MHCS) for all due to nonhomogeneous healthcare systems, socio-economic diversity, lack of funding and awareness. (Hajizadeh, Alam, \& Nandi, 2014). Although studies on antenatal care services (ANCs) have been conducted in Bangladesh, there is a dearth of literature on the competence of adequate ANCs and issues relevant to tribal women in Bangladesh, hence, this study. In low-income countries like Bangladesh, adequate antenatal visits are not common phenomena. Thus, issues involving the use of an adequate number of ANCs need timely attention. This study's results may help in adopting appropriate strategies to increase the number of prenatal care services for tribal women in Bangladesh.

\section{Aim and Objectives}

The study examines the adequacy of ANC practices and issues related to tribal women in Bangladesh Chittagong Hill Tracts (CHT).

\section{Research Methodology}

This study adopts a quantitative approach using a convenient sampling technique. Among women aged 15 to 49 who had at least one child (the child is one year old or younger), they were selected. A total sample of married tribal women $(n=556)$ and a semi-structured survey was used to acquire data. Using the SPSS (version 20) S/W, all data were analyzed. Associations were determined using the Chi-square test. To explore the factors related to adequate ANC services among the tribal women, a binary logistic regression analysis was done to evaluate the adequate ANC. Also, the odds ratio (OR) was calculated using multivariate analysis with a confidence interval (CI) of $95 \%$ to estimate the strength of the link between the dependent variables and the independent ones with significance at a p-value of $<0.10$. The formula of the Cochran has been used to measure the sample size as the minimum.

$$
\begin{gathered}
n=\frac{z^{2} p q}{d^{2}} \\
n=\frac{1.96 \times 1.96 \times 0.5 \times 0.5}{0.05 \times 0.05}=384
\end{gathered}
$$

With a $50 \%$ addition, the calculated sample size is 576 (i.e. 384+192). From the 25 upazillas, samples were taken from 556 families and due to the absence of the mother at home, 20 families were left out, respectively.

\section{Dependent Variables}

Adequacy for ANC: In the first 12 weeks of pregnancy, women receive four prenatal care appointments.

\section{Independent Variables}

Wealth Index, the first marriage age, family members, method of family planning, respondent age, women's occupation, location, husband's occupation, media disclosure, women's education, husband's education, location, the closest location for health care, religion, tribal group, birth order (no. child), were regarded as independent variables.

\section{Ethical Considerations}

The advanced studies board gave written permission to perform the research (Ref no: 27/Edu/IU-2013/828) dated on 19.02.2013) 


\subsection{Background of the Respondents}

The results show that urban and rural participants were $20 \%$ and $80 \%$, respectively. Participants aged 15-24 years and 25-34 years account for $43 \%$ and $49.5 \%$, respectively. For educational status, $28.8 \%$ of participants only have secondary education. Husbands of most of the women $(53.4 \%)$ are farmers. The unemployment rate among these women was $94.2 \%$, and $35.8 \%$ are residents within $05 \mathrm{~km}$. More so, thirty-eight per cent of women are middle class.

Table1 shows that greater numbers of women $(70.1 \%)$ did not try to find ANC services for pregnancy duration. However, only $29.9 \%$ of these tribal women searched for ANC while pregnant. Table 2 presents that $13.5 \%$ of women joined ANC services four times or more during pregnancy, while 16.4\% of women had 1-3 antenatal visits for the period of pregnancy.

Table 3 illustrates the relationship between demographic data and the adequacy of ANC facilities for Bangladeshi's tribal women. This study reports that the respondent age, first marriage age of respondent were positive and significantly linked to ANC facilities' adequacy. Nevertheless, the connections between family members and ANC facilities were not relevant.

Table 1 - Percentage Distribution of Antenatal Care Seeking

\begin{tabular}{lcc}
\hline Variable Name & $\mathrm{N}$ & $\%$ \\
\hline ANC visit & & \\
No & 390 & 70.1 \\
Yes & 166 & 29.9 \\
\hline Total & 556 & 100.0 \\
\hline
\end{tabular}

Table 2 - Percentage Adequacy Allocation to ANC

\begin{tabular}{lcc}
\hline Variable Name & $\mathrm{N}$ & $\%$ \\
\hline Adequacy for ANC & & \\
Never visit & 390 & 70.1 \\
Adequate visit $(4>=)$ & 75 & 13.5 \\
Inadequate visit $(1-3)$ & 91 & 16.4 \\
\hline Total & 556 & 100.0 \\
\hline
\end{tabular}

Table 3 - Relationship between Demographic Characteristics and Adequacy for ANC Seeking

\begin{tabular}{lcccccc}
\hline Demographic Characteristics & Total & \multicolumn{2}{c}{ Number of ANC Visits } & $\chi^{2}$ & P-Value \\
\hline & & No visits & $>3$ visits & $<=3$ visits & & \\
Respondent's Age & & & & & 8.980 & .062 \\
$\quad<25$ & 239 & $164(68.6 \%)$ & $29(12.1 \%)$ & $46(19.2 \%)$ & & \\
$\quad 25-34$ & 275 & $196(71.3 \%)$ & $44(16.0 \%)$ & $35(12.7 \%)$ & & \\
$\quad 35+$ & 42 & $30(71.4 \%)$ & $2(4.8 \%)$ & $10(23.8 \%)$ & & \\
First Marriage Age & & & & & 4.784 & .091 \\
$\quad<18$ & 120 & $89(74.2 \%)$ & $9(7.5 \%)$ & $22(18.3 \%)$ & & \\
$\quad 18+$ & 436 & $301(69.0 \%)$ & $66(15.1 \%)$ & $69(15.8 \%)$ & & \\
Family members & & & & & 1.285 & .526 \\
$\quad<5$ & 361 & $249(69.0 \%)$ & $53(14.7 \%)$ & $59(16.3 \%)$ & & \\
$\quad 5+$ & 195 & $141(72.3 \%)$ & $22(11.3 \%)$ & $32(16.4 \%)$ & & \\
Parity & & & & & 1.914 & .384 \\
$\quad$ One to Two & 418 & $288(68.9 \%)$ & $61(14.6 \%)$ & $69(16.5 \%)$ & & \\
$\quad$ Three and More & 138 & $102(73.9 \%)$ & $14(10.1 \%)$ & $22(15.9 \%)$ & & \\
\hline Total & 556 & $390(70.1 \%)$ & $75(13.5 \%)$ & $91(16.4 \%)$ & & \\
\hline
\end{tabular}


Table 4 - Relationship between Socio-economic Characteristics and Adequacy for ANC services

\begin{tabular}{|c|c|c|c|c|c|c|}
\hline \multirow[t]{2}{*}{ Socio-economic Characteristics } & \multirow[t]{2}{*}{ Total } & \multicolumn{3}{|c|}{ Number of ANC Visits } & \multirow{3}{*}{$\begin{array}{c}\chi^{2} \\
146.224\end{array}$} & \multirow{2}{*}{ P-Value } \\
\hline & & No visits & $>3$ visits & $<=3$ visits & & \\
\hline Wealth Index & & & & & & .000 \\
\hline Poor & 223 & $209(93.7 \%)$ & $4(1.8 \%)$ & $10(4.5 \%)$ & & \\
\hline Middle & 162 & $113(69.8 \%)$ & $15(9.3 \%)$ & $34(21.0 \%)$ & & \\
\hline Rich & 171 & $68(39.8 \%)$ & $56(32.7 \%)$ & $47(27.5 \%)$ & & \\
\hline Women's education & & & & & 142.160 & .000 \\
\hline No formal education & 169 & $151(89.3 \%)$ & $2(1.2 \%)$ & $16(9.5 \%)$ & & \\
\hline Primary & 128 & $108(84.4 \%)$ & $7(5.5 \%)$ & $13(10.2 \%)$ & & \\
\hline Secondary & 160 & $104(65.0 \%)$ & $26(16.2 \%)$ & $30(18.8 \%)$ & & \\
\hline Higher (SSC+) & 99 & $27(27.3 \%)$ & $40(40.4 \%)$ & $32(32.3 \%)$ & & \\
\hline Husbands' education & & & & & 124.274 & .000 \\
\hline Illiterate & 76 & $69(90.8 \%)$ & $0(0.0 \%)$ & $7(9.2 \%)$ & & \\
\hline Primary & 87 & $76(87.4 \%)$ & $4(4.6 \%)$ & $7(8.0 \%)$ & & \\
\hline Secondary & 197 & $163(82.7 \%)$ & $12(6.1 \%)$ & $22(11.2 \%)$ & & \\
\hline Higher (SSC+) & 196 & $82(41.8 \%)$ & $59(30.1 \%)$ & $55(28.1 \%)$ & & \\
\hline Occupation of the women & & & & & 58.527 & .000 \\
\hline Who do not earn & 524 & $385(73.5 \%)$ & $58(11.1 \%)$ & $81(15.5 \%)$ & & \\
\hline Who earn & 32 & $5(15.6 \%)$ & $17(53.1 \%)$ & $10(31.2 \%)$ & & \\
\hline Husbands' occupation & & & & & 103.344 & .000 \\
\hline Agriculture & 297 & $247(83.2 \%)$ & $22(7.4 \%)$ & $28(9.4 \%)$ & & \\
\hline Business & 105 & $58(55.2 \%)$ & $19(18.1 \%)$ & $28(26.7 \%)$ & & \\
\hline Service & 100 & $37(37.0 \%)$ & $34(34.0 \%)$ & $29(29.0 \%)$ & & \\
\hline Day laborer & 54 & $48(88.9 \%)$ & $0(0.0 \%)$ & $6(11.1 \%)$ & & \\
\hline Residence & & & & & 97.775 & .000 \\
\hline Rural & 445 & $352(79.1 \%)$ & $33(7.4 \%)$ & $60(13.5 \%)$ & & \\
\hline Urban & 111 & $38(34.2 \%)$ & $42(37.8 \%)$ & $31(27.9 \%)$ & & \\
\hline Watching television & & & & & 100.251 & .000 \\
\hline No & 371 & $308(83.0 \%)$ & $18(4.9 \%)$ & $45(12.1 \%)$ & & \\
\hline Yes & 185 & $82(44.3 \%)$ & $57(30.8 \%)$ & $46(24.9 \%)$ & & \\
\hline Listening to the radio & & & & & 17.556 & .000 \\
\hline No & 512 & $371(72.5 \%)$ & $62(12.1 \%)$ & $79(15.4 \%)$ & & \\
\hline Yes & 44 & $19(43.2 \%)$ & $13(29.5 \%)$ & $12(27.3 \%)$ & & \\
\hline Distance to health facility $(\mathrm{km})$ & & & & & 95.039 & .000 \\
\hline$<5$ & 199 & $92(46.2 \%)$ & $51(25.6 \%)$ & $56(28.1 \%)$ & & \\
\hline $5-9$ & 104 & $78(75.0 \%)$ & $16(15.4 \%)$ & $10(9.6 \%)$ & & \\
\hline $10+$ & 253 & $220(87.0 \%)$ & $8(3.2 \%)$ & $25(9.9 \%)$ & & \\
\hline Total & 556 & $390(70.1 \%)$ & $75(13.5 \%)$ & $91(16.4 \%)$ & & \\
\hline
\end{tabular}

Table 4 depicts the connection between socio-economic aspects and the adequacy of prenatal care services. The result illustrates that wealth index, residence location, women's schooling, women's occupation, education for the husband, husband's occupation and distance to a health centre, mass media exposure are all positively associated and statistically significant. 
Table 5 - Association between Cultural and Behavioural Characteristics and Adequacy for ANC Seeking

\begin{tabular}{|c|c|c|c|c|c|c|}
\hline Culture and Behavioral Characteristics & Total & \multicolumn{3}{|c|}{ Number of ANC Visits } & $x^{2}$ & P-Value \\
\hline & & No visits & $>3$ visits & $<=3$ visits & \multirow[b]{2}{*}{3.629} & \multirow[b]{2}{*}{0.163} \\
\hline \multicolumn{5}{|l|}{ Religion } & & \\
\hline Buddhist & $499(100 \%)$ & $344(68.9 \%)$ & $71(14.2 \%)$ & $84(16.8 \%)$ & & \\
\hline Other & $57(100 \%)$ & $46(80.7 \%)$ & $4(7.0 \%)$ & $7(12.3 \%)$ & & \\
\hline \multicolumn{2}{|l|}{ Group of tribal } & & & & 17.925 & 0.006 \\
\hline Chakma & $331(100 \%)$ & $212(64.0 \%)$ & $58(17.5 \%)$ & $61(18.4 \%)$ & & \\
\hline Marma & $138(100 \%)$ & $107(77.5 \%)$ & $12(8.7 \%)$ & $19(13.8 \%)$ & & \\
\hline Tripura & $37(100 \%)$ & $28(75.7 \%)$ & $3(8.1 \%)$ & $6(16.2 \%)$ & & \\
\hline Other & $50(100 \%)$ & $43(86.0 \%)$ & $2(4.0 \%)$ & $5(10.0 \%)$ & & \\
\hline \multicolumn{5}{|c|}{ Family planning (Have you been used any family planning methods ever?) } & 26.333 & 0.000 \\
\hline Yes & $253(100.0 \%)$ & $150(59.3 \%)$ & $48(19.0 \%)$ & $55(21.7 \%)$ & & \\
\hline No & $303(100.0 \%)$ & $240(79.2 \%)$ & $27(8.9 \%)$ & $36(11.9 \%)$ & & \\
\hline Total & $556(100.0 \%)$ & $390(70.1 \%)$ & $75(13.5 \%)$ & $91(16.4 \%)$ & & \\
\hline
\end{tabular}

Table 5 demonstrates the relationship between the adequacy of prenatal care services and behavioural and sociocultural parameters. The study found that religion, tribal group, and family planning were positive and significantly linked to ANC facilities' adequacy.

Table 6 - Multinomial logistic regression results: socio-economic factors affecting adequate ANC visits

\begin{tabular}{|c|c|c|c|c|c|c|c|c|}
\hline \multirow{3}{*}{ Variables } & \multirow{3}{*}{ B } & \multicolumn{3}{|c|}{ Inadequate (1-3) visit } & \multirow{3}{*}{$\mathrm{B}$} & \multicolumn{3}{|c|}{$\begin{array}{c}\text { Adequate (4+) visit vs } \\
\text { not received ANC }\end{array}$} \\
\hline & & \multirow{2}{*}{$\operatorname{Exp}(\mathrm{B})$} & \multicolumn{2}{|c|}{$95 \%$ C.I } & & \multirow{2}{*}{$\operatorname{Exp}(\mathrm{B})$} & \multicolumn{2}{|c|}{$95 \%$ C.I. } \\
\hline & & & Lower & Upper & & & Lower & Upper \\
\hline \multicolumn{9}{|l|}{ Wealth index } \\
\hline (Poor) & & 1.00 & & & & 1.00 & & \\
\hline Middle & 1.725 & $5.614 * * *$ & 2.475 & 12.737 & 1.266 & $3.548 * *$ & 1.019 & 12.348 \\
\hline Rich & 1.852 & $6.375 * * *$ & 2.687 & 15.124 & 2.171 & $8.770 * * *$ & 2.640 & 29.140 \\
\hline \multicolumn{9}{|c|}{ Distance to health facility $(\mathrm{km})$} \\
\hline$(<5)$ & & 1.00 & & & & 1.00 & & \\
\hline $5-9$ & -1.724 & $.178 * * *$ & .076 & .417 & -.696 & $.498(\mathrm{~ns})$ & .214 & 1.161 \\
\hline $10>=$ & -1.495 & $.224 * * *$ & .114 & .442 & -2.139 & $.118 * * *$ & .044 & .314 \\
\hline \multicolumn{9}{|c|}{ Women's education } \\
\hline$\left(0-5^{\text {th }}\right)$ & & 1.00 & & & & 1.00 & & \\
\hline Secondary & .026 & $1.026(\mathrm{~ns})$ & .469 & 2.246 & .756 & $2.131(\mathrm{~ns})$ & .722 & 6.291 \\
\hline Higher & 1.180 & $3.256^{* *}$ & 1.226 & 8.643 & 2.083 & $8.032 * * *$ & 2.325 & 27.743 \\
\hline \multicolumn{9}{|c|}{ Husbands' education } \\
\hline$\left(0-5^{\text {th }}\right)$ & & 1.00 & & & & 1.00 & & \\
\hline Secondary & .077 & $1.080(\mathrm{~ns})$ & .468 & 2.490 & .360 & $1.433(\mathrm{~ns})$ & .374 & 5.487 \\
\hline Higher & .882 & $2.416^{*}$ & .897 & 6.511 & 1.209 & $3.350(\mathrm{~ns})$ & .766 & 14.651 \\
\hline \multicolumn{9}{|c|}{ Residence Location } \\
\hline Urban & .351 & $1.420(\mathrm{~ns})$ & .703 & 2.868 & .942 & $2.565^{* *}$ & 1.188 & 5.539 \\
\hline \multicolumn{8}{|c|}{ Family planning } & \\
\hline Yes & .456 & $1.578(\mathrm{~ns})$ & .903 & 2.759 & .623 & $1.864 *$ & .948 & 3.665 \\
\hline
\end{tabular}


Table 6 shows socio-economic variables influencing the philosophy of adequate prenatal care services among indigenous women in Bangladesh. The study shows that women's education and economic background, location, distance from the health centre, and family planning has had a positive effect on the provision of appropriate ANC services. Family planning methods and accommodation are of paramount importance to obtain adequate prenatal care services. Research proves that educated women have received appropriate ANC services, and Husband's schooling has the greatest importance in getting inadequate ANC.

\section{Discussion}

This research aimed to identify issues that had a major effect on the use of adequate ANCs by CHT indigenous women in Bangladesh. The study found that the effective use of ANC by indigenous women is closely related to the distance to medical services, the family's financial position, women's academic status, residential location, and family planning. Many researchers in developing countries have done similar research, including Bangladesh, which constitutes the highest global health emergencies of adverse birth outcomes (Mohammad, Zahura, \& Rahman, 2017; Akter, Yimyam, Chareonsanti, \& Tiansawad, 2018; Das, 2018).

In Bangladesh, poverty is deep and prevalent; hence, affordability is an issue (Sarker. et al., 2016). This finding agrees with previous research, which reports that limited available resources were channelled to essential daily needs rather than for ANC (Ogundairo, \& Jegede, 2016). This phenomenon can be attributed to the declining economic position of many indigenous women. This question can be easily overcome by addressing financial problems. Thus, the economic and social status of women is the key to the ANC. Such circumstances can be improved by developing viable 'eco-friendly' enterprises and strengthened by the decentralization of maternal health facilities and quick access to and complete access to ANC services in hilly regions

Antenatal care (ANC) is required to reduce maternal mortality (World Health Organization, 2016). Inadequate use of the ANC is directly linked to a lack of independence and empowerment for women (Hossain, \& Hoque, 2015). As a result, these women depend on their husbands for all decisions, including decisions related to the ANC use (Azuh, Fayomi, \& Yartey Ajayi, 2015; Ganle, Obeng, Segbefia, Mwinyuri, Yeboah, \& Baatiema, 2015).

There is a harsh area between the valleys and the mountains, and women have a long way to go to health care. This poses an obstacle towards visiting a health facility for ANC while pregnant, even though the zeal and keenness in these CHT Tribal Women. This zeal is further weakened by inaccessible road networks and inadequate means of transportation in these hard terrains. Hence, distance from the nearest public health facility is critical to receiving, appreciating and adopting ANCs among these tribal women. This is consistent with studies in Burkina Faso and Cameroon, where distance (beyond $15 \mathrm{~km}$ ) from the health facility and inadequate transportation significantly influences ANC services (Nsibu, Manianga, Kapanga, Mona, Pululu, \& Aloni, 2016).

Education in the need of adequate prenatal care services is very important, as observed in this study. Educated women utilize ANC services by regular ANC visits compared to their uneducated counterparts. This result is consistent with previous research demonstrating that education enhances maternal knowledge, thus compelling them for better and proper health care programs to reduce pregnancy and childbirth complications (Mohammad, Zahura, \& Rahman, 2017). Similar reports on the association between maternal educational level and ANC services attendance were also observed in studies carried out in Cameroon, Burkina Faso and Central Ethiopia (Nsibu, Manianga, Kapanga, Mona, Pululu, \& Aloni, 2016).

Another study observed that, with more education, women are most likely to have four or more trips to ANC during pregnancy, confirming findings of an earlier study on the effect of women's education on receiving ANC facilities (Islam \& Masud, 2018; Awasthi, Awasthi, Thapa, Saud, Pradhan, \& Khatry, 2018). In one study in Sindh, the education level was substantially connected with the timing of the first ANC visit among pregnant women; this shows that motherhood education is an important aspect that helps women become more involved with their ANC services (Noh, Kim, Lee, Akram, Shahid, Kwon, \& Stekelenburg, 2019). Hence, education is the sunlight that breeds awareness, acceptance, and adequate services in the ANC.

The current research indicates that residential areas (urban or rural) significantly affect ANC facilities. Furthermore, the analysis indicates that city dwellers can use adequate ANC services, as health services are available and accessible. This result concurs with earlier studies, which found that women living in urban areas were more likely to use ANC services as they are more experienced and have easier access to these health care services than their rural counterparts (Islam \& Masud, 2018; Jim, Kim, Lee, Akram, Shahid, Kwon, \& Jelle, 2019; Pulok, Sabah, Uddin, \& Enemark, 2016). These findings vividly show that easy access to information, knowledge and proximity to nearby health facilities for better ANC services by urban women distinguishes them from their rural counterparts. The present study also shows that women adopting family planning are likely to use ANC services better. 


\section{Conclusion}

This research concludes that education for women, residence, economic status, family planning and proximity to the nearby health facilities significantly determine the acceptable use of ANC facilities during pregnancy among Bangladeshi tribal women in hilly regions.

Education is the cornerstone of every economic growth and self-determination. Women's education on maternal health care and reproductive education can also promote ANC services' proper use. This research shows that when pregnant, most females fail to meet the minimum number of ANC services. There is a need to raise an understanding of the benefits of the ANC in the tribal communities. The Ministry of Health Services has an important role to play in raising awareness on this issue. ANC clinics should be easily accessible; transportation should be available to promote visits for pregnant women. The Bangladesh government can contribute to free family planning services and encourage couples to follow family planning methods. The village people's lifestyle and behavioural habits, especially in hilly areas, are quite different from those of the plain. Tribal groups belong to different ethnic, multilingual communities, profess diverse faith, and have unique cultures different from mainstream cultures. In general, the tribes of Bangladesh are isolated geographically, behaviorally, socially, economically, culturally, and politically from the Mainstream ways of living.

What a person sees and observes around him deliberately or unwittingly affects his/her life. Thus, environmental and surrounding healthcare practices are an important component of achieving ANC services. In this case, concrete plans should be drawn to ensure good ANC services and safe maternity for the backward and socially disadvantaged ethnic groups. The drawback of this research is that it was a retrospective analysis. It could not be checked whether the respondents gave the correct response or the wrong answer. The data is fine, but there might be some errors because of the respondents' recall bias. Some information received may be inaccurate due to the low educational level of the participants in the area. Besides that, there is also a tendency to be more ashamed of women in the hilly areas.

\section{Acknowledgement}

The author would like to acknowledge the International Islamic University Chittagong, Bangladesh.

\section{References}

Alkema, L., Chou, D., Hogan, D., Zhang, S., Moller, A. B., Gemmill, A., ... \& Say, L. (2016). Global, regional, and national levels and trends in maternal mortality between 1990 and 2015, with scenario-based projections to 2030: a systematic analysis by the UN Maternal Mortality Estimation Inter-Agency Group. The Lancet, 387(10017), 462-474.

Mahejabin, F., Parveen, S., \& Sajani, T. T. (2016). Ante-natal Care Practices in Some Selected Rural Areas of Bangladesh. Anwer Khan Modern Medical College Journal, 7(2), 6-11.

World Health Organisation. (2016). Maternal mortality. Fact sheet. Retrieved from http://www.who.int/mediacare/factsheets/fs34

United Nations Children's Fund, World Health Organization, World Bank. (2015). United Nations- -DESA Population Division. Levels and Trends in Child Mortality 2015. Geneva, Switzerland: World Health Organization. Retrieved from https://data.unicef.org/topic/maternal-health/antenatal-care

National Institute of Population Research and Training. (2016). Bangladesh Demographic and Health Survey 2014. Mitra and Associates, and ICF International. Dhaka, Bangladesh.

Karim, A. N. M. R., Kamal, S. M., \& Islam, M. R. (2018). Antenatal Care Practices with Associated Factors among Tribal Women of Bangladesh. American Journal of Applied Mathematics and Statistics, 6(4), 149-157.

World Health Organization. (2002) The World Health Report 2002: WHO Antenatal Care Randomized Controlled Trial: Manual for implementation of the New Model. Geneva, Switzerland: World Health Organization.

World Health Organization and United Nations Children's Fund. (2003). Antenatal Care in Developing Countries. Promises, Achievements and Missed Opportunities: An Analysis of Trends, Levels and Differentials. WHO \& UNICEF, Geneva, New York: WHO and UNICEF.

World Health Organization (2006). The World Health Report 2006: Provision of effective antenatal care. Geneva, Switzerland: World Health Organization. 
da Fonseca, C. R. B., Strufaldi, M. W. L., de Carvalho, L. R., \& Puccini, R. F. (2014). Adequacy of antenatal care and its relationship with low birth weight in Botucatu, São Paulo, Brazil: a case-control study. BMC pregnancy and childbirth, 14(1), 255.

Abbas, A. M., Rabeea, M., Abdel Hafiz, H. A., \& Ahmed, N. H. (2017). Effects of irregular antenatal care attendance in primiparas on the perinatal outcomes: a cross sectional study. Proceedings in Obstetrics and Gynecology, 7(2), 111.

Hajizadeh, M., Alam, N., \& Nandi, A. (2014). Social inequalities in the utilization of maternal care in Bangladesh: Have they widened or narrowed in recent years? International journal for equity in health, 13(1), 120.

Mohammad, K. A., Zahura, F. T., \& Rahman, M. M. (2017). Importance of maternal education on antenatal care visits in Bangladesh. Bangladesh Journal of Scientific Research, 30(1-2), 23-33.

Akter, M. K., Yimyam, S., Chareonsanti, J., \& Tiansawad, S. (2018). The challenges of prenatal care for Bangladeshi women: a qualitative study. International Nursing Review, 65(4), 534-541.

Das, T. R. (2016). Family planning program of Bangladesh: Achievements and challenges. South East Asia Journal of Public Health, 6(1), 1-2.

Sarker, B. K., Rahman, M., Rahman, T., Hossain, J., Reichenbach, L., \& Mitra, D. K. (2016). Reasons for preference of home delivery with traditional birth attendants (TBAs) in rural Bangladesh: a qualitative exploration. PloS one, 11(1), e0146161.

Ogundairo, J., \& Jegede, A. (2016). Socio-cultural challenges in accessing antenatal care by pregnant Fulani women in Ibarapa Central Local Government, Oyo-State, Nigeria. Ann Public Health Res, 3(3), 1043.

World Health Organization. (2016). WHO recommendations on antenatal care for a positive pregnancy experience. Geneva.

Kuhnt, J., \& Vollmer, S. (2017). Antenatal care services and its implications for vital and health outcomes of children: evidence from 193 surveys in 69 low-income and middle-income countries. BMJ open, 7(11), e017122.

Hossain, B., \& Hoque, A. A. (2015). Women empowerment and antenatal care utilization in Bangladesh. The Journal of Developing Areas, 109-124.

Azuh, D. E., Fayomi, O. O., \& Yartey Ajayi, L. (2015). Socio-cultural factors of gender roles in women's healthcare utilization in Southwest Nigeria. Open Journal of Social Sciences, 3, 105-117.

Ganle, J. K., Obeng, B., Segbefia, A. Y., Mwinyuri, V., Yeboah, J. Y., \& Baatiema, L. (2015). How intra-familial decision-making affects women's access to, and use of maternal healthcare services in Ghana: a qualitative study. BMC pregnancy and childbirth, 15(1), 173.

Nsibu, C. N., Manianga, C., Kapanga, S., Mona, E., Pululu, P., \& Aloni, M. N. (2016). Determinants of antenatal care attendance among pregnant women living in endemic malaria settings: experience from the Democratic Republic of Congo. Obstetrics and Gynecology International, 2016.

Islam, M. M., \& Masud, M. S. (2018). Determinants of frequency and contents of antenatal care visits in Bangladesh: Assessing the extent of compliance with the WHO recommendations. PloS one, 13(9), e0204752.

Awasthi, M. S., Awasthi, K. R., Thapa, H. S., Saud, B., Pradhan, S., \& Khatry, R. A. (2018). Utilization of antenatal Care Services in Dalit Communities in Gorkha, Nepal: a cross-sectional study. Journal of Pregnancy, 2018.

Noh, J. W., Kim, Y. M., Lee, L. J., Akram, N., Shahid, F., Kwon, Y. D., \& Stekelenburg, J. (2019). Factors associated with the use of antenatal care in Sindh province, Pakistan: A population-based study. PloS one, 14(4), e0213987.

Pulok, M. H., Sabah, M. N. U., Uddin, J., \& Enemark, U. (2016). Progress in the utilization of antenatal and delivery care services in Bangladesh: where does the equity gap lie? BMC pregnancy and childbirth, 16(1), 200. 